\title{
Welas Asih Diri dan Kesejahteraan Subjektif pada Remaja dengan Orang Tua Bercerai
}

\author{
Ayulanningsih, Karjuniwati \\ Program Studi Psikologi, Fakultas Kedokteran, Universitas Syiah Kuala, Banda Aceh
}

\begin{abstract}
Abstrak. Kesejahteraan subjektif merupakan elemen penting kesehatan mental pada remaja. Kesejahteraan subjektif yang tinggi pada remaja akan membantu pula dalam optimalisasi perkembangan. Penelitian ini bertujuan untuk mengetahui hubungan antara welas asih diri dan kesejahteraan subjektif pada remaja dengan orang tua bercerai di kota Banda Aceh. Subjek dalam penelitian ini berjumlah 40 orang remaja yang orang tuanya bercerai di kota Banda Aceh. Penelitian ini menggunakan metode penelitian kuantitatif. Metode pengumpulan data yang digunakan adalah non-probability sampling dengan teknik quota sampling dan snowball sampling. Hasil analisis data diuji dengan teknik korelasi Spearman. Hasil uji korelasi menunjukkan koefisien korelasi $(r)$ sebesar .348 dengan taraf signifikansi .028 $(p<.05)$. Hal ini menjelaskan bahwa terdapat hubungan antara welas asih diri dan kesejahteraan subjektif pada remaja dengan orang tua bercerai di kota Banda Aceh.
\end{abstract}

Kata Kunci: kesejahteraan subjektif, remaja yang orangtuanya bercerai, welas asih diri

\section{Self-Compassion and Subjective Well-Being in Adolescents with Divorced Parents}

Abstract. Subjective well-being is one of the important elements of mental health in adolescents. A high level of subjective well-being among adolescents will help them to optimize their development. This research aims to determine the relationship between self-compassion and subjective well-being in adolescents with divorced parent in Banda Aceh city. The samples of this research were 40 adolescents with divorced parent in Banda Aceh city. This research used quantitative methods. The data, however, was revealed by using the method of non-probability sampling with quota sampling and snowball sampling technique. Output data analysis applied the Spearman correlation technique. The result of correlation test showed a correlation coefficient $(r)$ by .348 with a significance level of $.028(p<.05)$. It means that there is a relation between self-compassion and subjective well-being among adolescent with divorced parent in Banda Aceh city.

Keywords: adolescents with divorced parent, self-compassion, subjective well-being

Korespondensi: Ayulanningsih. Email: ayulanningsih.id@gmail.com 
Angka perceraian di Indonesia meningkat setiap tahun. Berdasarkan data yang didapat dari Kementerian Agama, dalam kurun tahun 2010 - 2015, terjadi lebih dari 100,000 kasus perceraian di Indonesia (Baiquni, 2016). Peningkatan angka perceraian juga terjadi di provinsi Aceh. Permohonan cerai yang masuk ke Mahkamah Syar'iyah di seluruh Aceh pada tahun 2009 mencapai 2,555 kasus, sedangkan pada tahun 2015 bertambah menjadi 4,674 kasus, artinya terjadi peningkatan 2,119 kasus dalam kurun waktu lima tahun (Shaleh, 2018).

Angka perceraian juga meningkat di kota Banda Aceh. Pada tahun 2009, angka perceraian di kota Banda Aceh mencapai 185 kasus, sedangkan tahun 2015 meningkat menjadi 252 kasus. Perceraian merupakan kondisi dari pasangan suami istri, di antara penyebabnya ialah faktor usia muda, ekonomi, suami sering berlaku kasar, dan faktor belum mempunyai anak (Matondang, 2014).

Perceraian yang terjadi pada orang tua akan memunculkan permasalahanpermasalahan. Permasalahan akan berdampak lebih kompleks pada saat anak berusia remaja (Dewanti \& Suprapti, 2014). Remaja cenderung menghadapi dan menyembunyikan perasaannya dari orang lain, tetapi banyak juga dari mereka yang menunjukkan kemarahan secara terbuka (Banne \& Afiatin, 2014; Nasri et al., 2018). Kondisi orang tua bercerai akan memberi pengaruh negatif pada remaja. Perceraian pada orang tua menjadikan remaja berpotensi mengalami kegagalan akademis (Esmaeili et al, 2011), perasaan marah (Hamama \& Ronen-
Shenhav, 2012), tidak peka terhadap lingkungan, sulit menjadi fokus, mudah menyalahkan orang tua, ingin menang sendiri dan melakukan perilaku kenakalan (Untari et al, 2018), permasalahan emosional dan perilaku (Theunissen etal, 2017), hingga permasalahan fisik dan kesehatan (Haimi \& Lerner, 2016).

Berdasarkan hasil riset, anak yang dibesarkan dengan orang tua utuh dengan pernikahan yang stabil, cenderung akan mengembangkan kesejahteraan fisik, emosional, hingga akademik (Anderson, 2014). Namun sebaliknya, remaja dengan orang tua bercerai cenderung mengalami kesejahteraan subjektif yang rendah. Dewi dan Utami (2013) menyatakan bahwa berbagai macam afek negatif dapat dirasakan oleh remaja pascaperceraian orang tuanya, diantaranya timbul perasaan tidaknyaman, terguncang, terpukul, kecewa, sedih, tertekan, marah, takut, iri hati, tidak lega, dan merasa tidak puas dalam kondisi keluarga. Selain itu, riset menunjukkan bahwa remaja yang orang tuanya bercerai cenderung lebih rendah kepuasannya terhadap keluarga dan memiliki hambatan ekonomi lebih tinggi (Walper etal, 2015). Remaja juga kerap mengalami kebingungan atas kejelasan peran orang tua dan menghadirkan rasa tidak aman (Isik, 2016). Rasa sedih berkepanjangan hingga mengalami depresi merupakan dampak jangka panjang dari remaja yang memiliki orang tua bercerai (Uphold-Carrier \&Utz, 2012). Berdasarkan hasil riset tersebut, tampak bahwa remaja dengan orang tua bercerai cenderung lebih berisiko dalam membangun kesejahteraan subjektifnya. 
Afek negatif yang sering dirasakan oleh remaja dengan orang tua bercerai dapat menurunkan tingkat kesejahteraan subjektif dari remaja tersebut Yárnoz-Yaben dan Garmendia (2016) menemukan bahwa kesejahteraan subjektif remaja dengan orang tua bercerai mengalami dampak negatif yang lebih besar daripada remaja dengan keluarga utuh. Studi yang dilakukan oleh Afifi et al. (2007) memaparkan hasil bahwa, tingkat kesejahteraan subjektif pada remaja cenderung rendah ketika remaja memiliki persepsi kuat pada ketegangan orang tua yang membicarakan tentang perceraian.

Terdapat beberapa hal yang dapat berpengaruh pada kesejahteraan subjektif remaja dengan orang tua bercerai. Studi yang dilakukan oleh Astuti dan Anganthi (2016) menemukan beberapa faktor, antara lain: (a) strategi koping, (b) faktor ekonomi, (c) jenis kelamin, (d) pola asuh orang tua, dan (e) dukungan sosial. Faktor lain yang dapat memengaruhi kesejahteraan remaja ialah welas asih diri (self-compassion) (López et al., 2018; Mülazým \& Eldeleklioðlu, 2016; Reginasari \& Gusniarti, 2016). Selain itu, studi oleh Bluth dan Blanton (2015) menegaskan bahwa welas asih diri memiliki korelasi signifikan dengan keseluruhan kesejahteraan emosi pada konteks remaja. Penelitian yang dilakukan oleh Sun et al. (2016) mengkaji tentang remaja yang membuktikan bahwa welas asih diri berkorelasi pada kesejahteraan remaja.

Selain studi korelasional, ternyata melalui penelitian eksperimen, terbukti bahwa welas asih diri memiliki efek untuk meningkatkan kesejahteraan subjektif pada diri individu. Ada perbedaan yang signifikan antara kelompok yang mendapatkan intervensi welas asih diri dan kelompok kontrol (Karakasidou \& Stalikas, 2017). Hal ini semakin menegaskan bahwa welas asih diri memang memiliki peran yang vital dalam peningkatan kesejahteraan subjektif seseorang.

Emosi negatif yang dirasakan oleh remaja dapat diatasi dengan terlebih dahulu menerima segala kenyataan dan masalah yang sedang terjadi, serta memiliki sikap belas kasih terhadap diri sendiri. Sikap belas kasih ini dapat menjadi langkah awal dalam mengatasi emosi negatif tersebut. Sikap belas kasih ini sering disebut welas asih diri (Ramadhani \& Nurdibyanandaru, 2014). Lebih lanjut, Neff menjelaskan bahwa welas asih diri dapat membantu individu untuk tidak mencemaskan kekurangan yang ada pada dirinya sendiri, karena orang yang memiliki welas asih diri dapat memperlakukan dirinya dan orang lain secara positif serta memahami ketidaksempurnaan manusia (Neff, 2011). Dengan demikian, ketika seorang remaja memiliki welas asih diri pada dirinya sendiri, hal ini akan mendorong munculnya penerimaan atas kondisi yang terjadi. Dengan demikian, kesejahteraan subjektif akan lebih memungkinkan untuk dicapai.

Peneliti belum menemukan adanya penelitian welas asih diri dan kesejahteraan subjektif khususnya pada subjek remaja dengan orang tua bercerai. Berdasarkan alasan tersebut 
dan beberapa uraian di atas, peneliti tertarik untuk melakukan penelitian lebih lanjut terkait hubungan antara welas asih diri dan kesejahteraan subjektif pada remaja dengan orang tua bercerai di kota Banda Aceh. Hipotesis penelitian yang diajukan adalah ada hubungan positif antara welas asih diri dan kesejahteraan subjektif.

\section{Metode}

\section{Desain penelitian}

Penelitian ini merupakan penelitian kuantitatif dengan jenis penelitian korelasi. Penentuan sampel pada penelitian ini menggunakan teknik snowball sampling. Teknik sampling tersebut merupakan teknik penentuan sampel yang mula-mula jumlahnya kecil, kemudian membesar (Sugiyono., 2014). Ada kriteria yang ditetapkan dalam snowball sampling, yakni remaja dengan orang tua yang telah bercerai. Pemilihan jenis sampling ini akan memudahkan peneliti saat mencari subjek dengan karakteristik tersebut yang jumlahnya terbatas di populasi.

\section{Subjek penelitian}

Jumlah sampel yang ditentukan dalam penelitian ini sebanyak 40 responden dengan kriteria sampel (a) remaja berusia 13 - 18 tahun yang memiliki orang tua bercerai, (b) perceraian terjadi di wilayah kota Banda Aceh, dan (c) usia perceraian minimal satu tahun.

\section{Metode pengumpulan data}

Metode pengumpulan data yang digunakan adalah metode survei dengan menggunakan beberapa skala psikologi. Skala pertama adalah Self-compassion Scale yang disusun oleh Neff (2003a) berjumlah 26 butir yang terdiri dari lima pilihan jawaban. Nilai Alpha Cronbach pada skala ini adalah .78 untuk subskala Self-Kindness; .80 untuk subskala Common Humanity; dan .81 untuk subskala Mindfulness.

Kemudian, untuk pengukuran kesejahteraan subjektif menggunakan dua skala. Skala kesejahteraan subjektif pertama adalah The Satisfaction With Life Scale (SWLS) yang disusun oleh Diener et al (1985) berjumlah lima butiryang terdiri dari tuju pilihan jawaban. Skor Alpha Cronbach untuk skala ini adalah .87. Skala kesejahteraan subjektif kedua adalah Scale of Positive and Negative Experience (SPANE) yang disusun oleh Diener etal (2009) berjumlah 12 butir yang terdiri dari lima pilihan jawaban. Skor Alpha Cronbach skala ini, untuk subskala Afek Positif adalah .84; untuk subskala Afek Negatif sebesar.80; serta untuk Afekyang Seimbang sebesar .88.

\section{Metode analisis data}

Berdasarkan data yang diperoleh, peneliti menggunakan teknik analisis Product-Moment Correlation dari Pearson. Halini sesuai dengan tujuan dan hipotesis penelitian yang diajukan.

\section{Hasil}

\section{Deskripsi data}

Berikut ini adalah deskripsi subjek penelitian berdasarkan beberapa kategori. Kriteria pertama adalah jenis kelamin. 


\section{Tabel 1}

Deskripsi Subjek Penelitian berdasarkan Jenis Kelamin

\begin{tabular}{lcc}
\hline \multicolumn{1}{c}{ Kategorisasi } & $n$ & $\%$ \\
\hline Laki-laki & 24 & 60 \\
Perempuan & 16 & 40 \\
$N$ & 40 & 100 \\
\hline
\end{tabular}

\section{Tabel 2}

\section{Deskripsi Subjek Penelitian berdasarkan Usia}

\begin{tabular}{lcc}
\hline \multicolumn{1}{c}{ Kategorisasi usia } & $n$ & $\%$ \\
\hline Usia 13 tahun & 3 & 7.5 \\
Usia 14 tahun & 6 & 15 \\
Usia 15 tahun & 5 & 12.5 \\
Usia 16 tahun & 9 & 22.5 \\
Usia 17 tahun & 8 & 20 \\
Usia 18 tahun & 9 & 22.5 \\
$N$ & 40 & 100 \\
\hline
\end{tabular}

Berdasarkan Tabel 1, tampakbahwa subjek dengan sebaran frekuensi yang hampir sama. penelitian berjenis kelamin laki-laki cenderung lebih mendominasi. Berdasarkan Tabel 2, tampak Selanjutnya, peneliti melakukan analisis deskripsi bahwa proporsi di setiap kategori relatif seimbang untuk rentang waktu perceraian orang tua dilihat dari kondisi terkini.

\section{Tabel 3}

Deskripsi Rentang Waktu Perceraian Orang Tua

\begin{tabular}{|c|c|c|}
\hline Kategorisasi & $n$ & $\%$ \\
\hline 1 tahun & 6 & 15 \\
\hline 2 tahun & 18 & 45 \\
\hline 3 tahun & 11 & 27.5 \\
\hline 4 tahun & 3 & 7.5 \\
\hline 5 tahun & 2 & 5 \\
\hline$N$ & 40 & 100 \\
\hline
\end{tabular}

Pada Tabel 3, dapat diketahui bahwa rentang waktu perceraian orang tua subjek penelitian ini memiliki persentase tertinggi pada kategori rentang waktu dua tahun, sementara persentase paling rendah berada pada kategori rentang waktu lima tahun.

\section{Tabel 4}

Deskripsi Kategorisasi Self-compassion

\begin{tabular}{lcccc}
\hline \multirow{2}{*}{ Kategorisasi } & \multicolumn{2}{c}{ Kesejahteraan subjektif } & \multicolumn{2}{c}{ Welas asih diri } \\
\cline { 2 - 5 } & $n$ & $\%$ & $n$ & $\%$ \\
\hline Rendah & 27 & 67.5 & 26 & 65 \\
Sedang & 8 & 20 & 13 & 32.5 \\
Tinggi & 5 & 12.5 & 1 & 2.5 \\
$N$ & 40 & 100 & 40 & 100 \\
\hline
\end{tabular}


Berdasarkan Tabel 4, ditemukan adanya fakta yang menarik pada remaja dengan orang tua bercerai. Tabel di atas menunjukkan bahwa lebih dari separuh subjek penelitian memiliki kategorisasi rendah pada kedua variabel, baik variabel kesejahteraan subjektif maupun welas asih diri.

\section{Uji hipotesis}

Hasil uji hipotesis menunjukkan nilai signifikansi sebesar $(p)=.028<.05$ dengan nilai koefisien korelasi sebesar $(r)=.348$. Hal ini berarti bahwa, ada hubungan positif antara welas asih diri dan kesejahteraan subjektif pada remaja dengan orang tua bercerai di kota Banda Aceh. Kemudian, ditemukan bahwa nilai $r$ Square sebesar $\left(r^{2}\right)=.644$. Hal tersebut mengindikasikan besaran sumbangan efektif welas asih diri terhadap kesejahteraan subjektif, yakni sebesar $64.4 \%$.

\section{Pembahasan}

Hasil penelitian ini menunjukkan bahwa hipotesis diterima, artinya terdapat hubungan antara welas asih diri dan kesejahteraan subjektif pada remaja dengan orang tua bercerai di kota Banda Aceh. Hasil dari riset ini menguatkan temuan-temuan sebelumnya. Hal ini senada dengan hasil penelitian dari Stapleton et al. (2018) yang menyatakan bahwa aspek dari welas asih diri yakni kebaikan diri (selfkindness) dan kesadaran penuh (mindfulness) ternyata berperan signifikan sebagai prediktor kesejahteraan individu. Hal tersebut dikuatkan pula oleh hasil riset Mülazým dan Eldeleklioðlu
(2016) yang menyatakan bahwa kepuasan hidup dan kebahagiaan diprediksi oleh welas asih diri. Bahkan, hasil riset meta-analisis yang dilakukan pada 19 penelitian, menunjukkan hasil yang serupa (Marsh et al. (2017). Oleh sebab itu, secara eksplisit, tampak adanya peran dari welas asih diri terhadap kesejahteraan subjektif individu, bahkan pada remaja yang memiliki orang tua bercerai.

Welas asih diri ternyata dapat membantu remaja yang mengalami beragam permasalahan hidup agar tetap melihat diri sendiri secara positif, terlibat dalam kegiatan yang menyenangkan, serta mengembangkan relasi positif dengan orang lain (Klingle \& Van Vliet, 2019). Hal ini berkaitan dengan pengembangan afek positif dan kepuasan hidup pada kesejahteraan subjektif. Selain itu, afek positif juga berkaitan dengan kemampuan untuk bertahan pada situasi yang sulit. Welas asih diri dapat membantu remaja untuk melewati situasi sulit tersebut dengan mengembangkan rasa ingin tahu dan resiliensi (Bluth et al., 2018). Berdasarkan paparan tersebut, maka tampak dinamika dari temuan utama untuk uji hipotesis.

Secara deskriptif, hasil penelitian menunjukkan bahwa persentase terbanyak welas asih diri berada pada kategori rendah. Banyaknya sampel penelitian yang menunjukkan intensitas welas asih diri yang rendah pada subjek penelitian dapat dipengaruhi oleh usia subjek yang masih berada pada tahap remaja. Hal tersebut sesuai dengan 
penelitian yang dikemukakan oleh Neff (2003c) yang menyatakan bahwa masa remaja adalah periode kehidupan di mana level welas asih diri berada pada level terendah dibandingkan dengan periode kehidupan yang lain, hal ini disebabkan karena pada masa ini, welas asih diri mulai berkembang. Lebih lanjut, Neff (2003c) menjelaskan bahwa perkembangan kognitif yang dihadapi remaja umumnya diistilahkan dengan adanya egosentrisme remaja, serta adanya tekanan sosial yang erat kaitannya dengan adanya keinginan untuk dapat menyatu dengan teman sebaya, dan lain sebagainya. Ada dua bentuk egosentrisme remaja yang kemungkinan dapat memengaruhi terbentuknya welas asih diri. Pertama adalah audiens imajiner (imaginary audience), yaitu remaja membayangkan bahwa perilaku mereka adalah fokus dari perhatian orang lain. Bentuk yang kedua adalah fabel pribadi (personal fable), yaitu remaja percaya bahwa pengalaman mereka bersifat unik dan orang lain tidak mungkin memahami apa yang mereka alami. Dengan adanya egosentrisme tersebut, remaja cenderung akan lebih sulit untuk mengembangkan welas asih diri dalam dirinya.

Tinggi atau rendahnya welas asih diri seseorang dapat disebabkan oleh beberapa faktor. Menurut Neff (2003b), ada beberapa faktor yang dapat memengaruhi welas asih diri: (a) gender, (b) fase perkembangan/periode kehidupan, (c) lingkungan keluarga, dan (d) budaya. Kondisi lingkungan keluarga dapat menjadi salah satu faktor yang memengaruhi tingkat welas asih diri pada subjek penelitian. Individu yang tumbuh dalam pola pengasuhan yang penuh kasih sayang dan kehangatan di dalam keluarganya cenderung memiliki welas asih diri yang tinggi, dan begitu juga sebaliknya. Individu yang mengalami kehangatan di dalam keluarga akan memiliki hubungan yang saling mendukung. Oleh sebab itu, anak akan merasa bahwa ada pemahaman dan kasih sayang antar-anggota keluarga, sehingga cenderung memiliki welas asih diri yang lebih tinggi. Sebaliknya, individu yang kurang perhatian dan sangat kritis (atau mengalami perlakuan yang salah baik secara psikologis, seksual, maupun fisik ketika mereka masih anak-anak), maka individu tersebut akan cenderung memiliki level welas asih diri yang lebih rendah. Hal tersebut sesuai dengan hasil penelitian ini yang memperlihatkan bahwa, situasi perceraian yang terjadi pada remaja dapat menjadi faktor pendukung terhadap tinggi rendahnya tingkat welas asih diri pada remaja.

Individu dengan tingkat kesejahteraan subjektif yang rendah, umumnya lebih banyak mengalami emosi negatif dibandingkan dengan emosi positif dan merasa kurang puas terhadap kehidupannya. Individu dengan kesejahteraan subjektif yang rendah bukan berarti tidak pernah merasakan afek positif, tetapi lebih banyak merasakan emosi atau afek negatif di dalam kehidupannya. Berbeda dengan individu dengan tingkat kesejahteraan subjektif yang tinggi. Pada umumnya individu tersebut lebih banyak mengalami afek positif dibandingkan 
dengan afek negatif dan merasa puas terhadap kehidupannya. Individu dengan kesejahteraan subjektif yang tinggi bukan berarti tidak pernah merasakan afek negatif, mereka lebih banyak merasakan emosi atau afek positif dibandingkan afek negatif (Dewi \& Utami, 2013). Berdasarkan hasil penelitian ini, dapat dikatakan bahwa remaja yang terlibat dalam penelitian ini sebagian besar memiliki kesejahteraan subjektif yang rendah.

Diener (2000) menyatakan bahwa individu dengan tingkat kesejahteraan subjektif yang rendah, memandang rendah hidupnya dan menganggap peristiwa yang terjadi sebagai hal yang tidak menyenangkan, oleh sebab itu, timbul emosi yang tidak menyenangkan seperti kecemasan, depresi, dan kemarahan. Di sisi lain, individu dengan kesejahteraan subjektif yang tinggi, pada umumnya memiliki sejumlah kualitas yang mengagumkan bahwa individu ini akan lebih mampu mengontrol emosinya dan menghadapi berbagai peristiwa dalam hidup dengan lebih baik.

Ada beberapa kelemahan dalam penelitian ini. Pertama adalah berkaitan dengan jumlah subjek yang masih terbatas dan belum mewakili kota Banda Aceh secara proporsional. Selanjutnya adalah belum seimbangnya jumlah subjek yang mewakili kedua jenis kelamin. Kemudian, kelemahan selanjutnya adalah tidak adanya data demografis yang menunjukkan remaja bertempat tinggal dengan ayah atau ibu. Peran orang tua dimungkinkan akan berpengaruh pada kondisi remaja. Oleh sebab itu, kelemahan dalam penelitian ini dapat dijadikan masukan bagi penelitian selanjutnya.

\section{Simpulan}

Berdasarkan hasil penelitian, maka dapat disimpulkan bahwa hipotesis penelitian ini diterima yaitu terdapat hubungan antara welas asih diri dan kesejahteraan subjektif pada remaja yang orang tuanya bercerai di kota Banda Aceh. Hasil penelitian ini menemukan bahwa terdapat hubungan positif antara welas asih diri dengan kesejahteraan subjektif, hal ini dapat diartikan bahwa semakin tinggi welas asih diri maka akan semakin tinggi tingkat kesejahteraan subjektif, dan sebaliknya semakin rendah welas asih diri maka akan semakin rendah tingkat kesejahteraan subjektif. Hasil penelitian ini juga menunjukkan bahwa sebagian besar remaja yang orang tuanya bercerai di kota Banda Aceh berada pada tingkatan welas asih diri yang rendah dan sebagian kecil berada pada tingkatan welas asih diri yang tinggi, sementara untuk variabel kesejahteraan subjektif, sebagian besar remaja yang orang tuanya bercerai berada pada kategori rendah, sebagian kecil berada pada kategori tinggi.

\section{Saran}

Pada remaja yang orang tuanya bercerai agar dapat menyayangi diri sendiri, tidak menghakimi diri sendiri, serta tidak terlalu bersikap berlebihan terhadap situasi yang terjadi. Selain itu, subjek diharapkan dapat membangun welas asih diri pada diri sendiri 
untuk meningkatkan kesejahteraan subjektifnya. Kepada peneliti selanjutnya yang ingin melakukan penelitian dengan variabel yang sama, maka dapat diteliti dengan menggunakan metode kualitatif melalui observasi dan wawancara untuk memperdalam hasil variabel penelitian, terutama berkaitan dengan dinamika atau gambaran kesejahteraan subjektif dan welas asih diri pada remaja yang orang tuanya bercerai. Selanjutnya, subjek penelitian tidak hanya remaja, akan tetapi juga dapat dilakukan pada orang dewasa yang mengalami perceraian langsung agar hasil penelitian lebih variatif. Selain itu, variabel welas asih diri dan kesejahteraan subjektif juga dapat dikaji dengan faktor-faktor lain seperti religiusitas, optimisme, harga diri, serta berbagai faktor lainnya sehingga dapat memperkaya penelitian.

\section{Referensi}

Afifi, T. D., McManus, T., Hutchinson, S., \& Baker, B. (2007). Inappropriate parental divorce disclosures, the factors that prompt them, and their impact on parents' and adolescents' well-being. Communication Monographs, 74(1), 78-102. https:// doi.org/10.1080/03637750701196870

Anderson, J. (2014). The impact of family structure on the health of children: Effects of divorce. Linacre Quarterly, 81(4), 378-387. https://doi.org/https:/ / d o i . o r g / 10.1179 / 0024363914Z.00000000087

Astuti, Y., \& Anganthi, N. R. N. (2016). Subjective well-being pada remaja dari keluarga broken home. Jurnal Penelitian Humaniora, 17(2), 161-175. https:// doi.org/https://doi.org/10.23917/ humaniora.v17i2.2508
Baiquni. (2016). Angka perceraian meningkat lima tahun terakhir. Dream.Co.Id. http:// www.dream.co.id/news/angkaperceraian-meningkat-lima-tahunterakhir-1601200.html

Banne, 0. \& Afiatin, T. (2014). Resiliensi remaja yang memiliki bercerai. Universitas Gajah Mada.

Bluth, K., \& Blanton, P. W. (2015). The influence of self-compassion on emotional wellbeing among early and older adolescent males and females. The Journal of Positive Psychology, 10(3), 219-230. https:// doi.org/https://doi.org/10.1080/ 17439760.2014.936967

Bluth, K., Mullarkey, M., \& Lathren, C. (2018). Self-compassion: A potential path to adolescent resilience and positive exploration. Journal of Child and Family Studies, 27(9), 3037-3047. https:// doi.org/https://doi.org/10.1007/ s10826-018-1125-1

Dewanti, P. A., \& Suprapti, V. (2014). Resiliensi remaja putri terhadap problematika pasca bercerai. Jurnal Psikologi Pendidikan Dan Perkembangan, 3(3), 164-171.

Dewi, P. \& Utami, M. (2013). Subjective well being anak dari orangtua yang bercerai. Jurnal Psikologi, 35(2), 194-212. https:/ /doi.org/https://doi.org/10.22146/ jpsi.7952

Diener, E. (2000). Subjective well-being.the science of happiness and a proposal for a national index. American Psychologist, 55, 34-43. https://doi.org/https:// doi.org/10.1037/0003-066X.55.1.34

Diener, E., \& Biswas, D. R. (2009). Scale of positive and negative experience (SPANE). http:// internal.psychology.illinois.edu / ediener/SPANE.html

Diener, E. D., Emmons, R. A., Larsen, R. J., \& Griffin, S. (1985). The satisfaction with life scale. Journal of Personality Assessment, 49(1), 71-75. https:// doi.org/10.1207/s15327752jpa4901_13 
Esmaeili, N. S., Yaacob, S. N., Juhari, R., \& Mansor, M. (2011). Post-divorce parental conflict, economic hardship and academic achievement among adolescents of divorced families. Asian Social Science, 7(12), 119. https:// doi.org/10.5539/ass.v7n12p119

Haimi, M., \& Lerner, A. (2016). The impact of parental separation and divorce on the health status of children, and the Ways to Improve it. Journal of Clinical \& Medical Genomics, 4(1), 1-7. https://doi.org/ https: //doi.org/10.4172/24 72128x.1000137

Hamama, L., \& Ronen-Shenhav, A. (2012). Selfcontrol, social support, and aggression among adolescents in divorced and twoparent families. Children and Youth Services Review, 34(5), 1042-1049. https://doi.org/https://doi.org/ 10.1016/j.childyouth.2012.02.009

Isik, M. A. (2016). The socio-psychological impact of divorce on school children through analysis of interviews implemented to students and school psychologists in Tirana/Albania. European Journal of Interdisciplinary Studies, 2(4), 137-144. https://doi.org/ 10.26417/ejis.v6i1.p137-144

Karakasidou, E., \& Stalikas, A. (2017). The effectiveness of a pilot self-compassion program on well being components. Psychology, 8(4), 538-549. https:// doi.org/https://doi.org/10.4236/ psych.2017.84034

Klingle, K. E., \& Van Vliet, K. J. (2019). Selfcompassion from the adolescent perspective: A qualitative study. Journal of Adolescent Research, 34(3), 323-346. https://doi.org/https://doi.org/ 10.1177/0743558417722768

López, A., Sanderman, R., Ranchor, A. V., \& Schroevers, M. J. (2018). Compassion for others and self-compassion: Levels, correlates, and relationship with psychological well-being. Mindfulness, 9(1), 325-331. https://doi.org/https:// doi.org/10.1007/s12671-017-0777-z
Marsh, I. C., Chan, S. W. Y., \& Macbeth, A. (2017). Self-compassion and psychological distress in adolescents - a meta-analysis. Mindfulness, 9(4), 1011-1027. https:// doi.org/https://doi.org/10.1007/ s12671-017-0850-7

Matondang, A. (2014). Faktor-faktor yang mengakibatkan perceraian dalam perkawinan. JPPUMA Jurnal Ilmu Pemerintahan Dan Sosial Politik Universitas Medan Area, 2(2), 141-150. https://doi.org/https://ojs.uma.ac.id/ index.php/jppuma/article/view/919

Mülazým, Ö. C., \& Eldeleklioðlu, J. (2016). What is the role of self-compassion on subjective happiness and life satisfaction? Journal of Human Sciences, 13(3), 3895. https://doi.org/https:// doi.org/10.14687/jhs.v13i3.4001

Nasri, S. A., Nisa, H., \& Karjuniwati. (2018). Bagaimana remaja memaafkan perceraian orang tuanya: Sebuah studi fenomenologis. SEURUNE: Jurnal Psikologi Unsyiah, 1(2), 102-120.

Neff, K. D. (2003a). Development and validation of a scale to measure self-compassion. Self and Identity, 2, 223-250. https://doi.org/ $10.1080 / 15298860309027$

Neff, K. D. (2003b). Development and validation of a scale to measure selfcompassion. Selfand Identity, 2, 223-250. h t tp s : / / doi .org / 10.1080 / 15298860390209035

Neff, K. D. (2003c). Self-compassion: An alternative conceptualization of a healthy attitude toward oneself. Self and Identity, 2, 85-101. https://doi.org/ $10.1080 / 15298860390129863$

Neff, K. D. (2011). Self-compassion, self-esteem, and well-being. Social and Personality Psychology Compass, 5(1), 1-12. https:/ /doi.org/https://doi.org/10.1111/ j.1751-9004.2010.00330.x

Ramadhani, F., \& Nurdibyanandaru, D. (2014). Pengaruh self-compassion terhadap kompetensi emosi remaja akhir. Jurnal 
Psikologi Klinis Dan Kesehatan Mental, 3(3), 120-126.

Reginasari, A., \& Gusniarti, U. (2016). Subjective well-being from the perspective of selfcompassion in adolescents. Unity, Diversity and Culture: Research and Scholarship Selected from the 22nd Congress of the International Association for Cross-Cultural Psychology, 465-468.

Shaleh, M. (2018). Angka perceraian di Aceh terus meningkat: Panitera Mahkamah Syar'iyah Aceh berharap ada jalan keluar. ModusAceh.Com.

Stapleton, B. P., Richardson, K., \& Kalla, M. (2018). How aspects of self-compassion contribute to wellbeing and the effect of age. International Journal of Health and Caring, 18(3), 1-12. https:// pdfs.semanticscholar.org/d 7aa / f41f6dc0741f8e76c3e8cbfef650ab47e488.pdf

Sugiyono. (2014). Metode penelitian pendekatan kuantitatif, kualitatif, dan $R \& D$. Alfabeta.

Sun, X., Chan, D. W., \& Chan, L. K. (2016). Selfcompassion and psychological wellbeing among adolescents in Hong Kong: Exploring gender differences. Personality and Individual Differences, 101, 288-292. https://doi.org/https:// doi.org/10.1016/j.paid.2016.06.011

Theunissen, M. H. C., Klein Velderman, M., Cloostermans, A. P. G., \& Reijneveld, S. A. (2017). Emotional and behavioural problems in young children with divorced parents. European Journal of Public
Health, 27(5), 840-845. https://doi.org/ https://doi.org/10.1093/eurpub/ck

Untari, I., Putri, K. P. D., \& Hafiduddin, M. (2018). Dampak perceraian orang tua terhadap kesehatan psikologis remaja. Profesi (Profesional Islam): Media Publikasi Penelitian, 15(2), 106. https://doi.org/ 10.26576/profesi.272

Uphold-Carrier, H., \& Utz, R. (2012). Parental divorce among young and adult children: A long-term quantitative analysis of mental health and family solidarity. Journal of Divorce and Remarriage, 53(4), 247-266. https://doi.org/https:/ / d o i . o r g / 10.1008 / 10502556.2012.66327

Walper, S., Thönnissen, C., \& Alt, P. (2015). Effects of family structure and the experience of parental separation: A study on adolescents' well-being. Comparative Population Studies, 40(3), 335-364. https://doi.org/https:// doi.org/10.12765/CPoS-2015-12en

Yárnoz-Yaben, S., \& Garmendia, A. (2016). Parental divorce and emerging adults' subjective well-being: The role of "carrying messages". Journal of Child and Family Studies, 25(2), 638-646. h t tps://doi.org / https:// psycnetapa.org/doi/10.1007/s10826015-0229-0

Received 20 December 2019

Revised 30 May 2020 Accepted 30 May 2020 
